\title{
THE AMERICAN BURYING BEETLE, NICROPHORUS AMERICANUS: STUDIES ON THE NATURAL HISTORY OF A DECLINING SPECIES*
}

\author{
By Andrea J. Kozol, Michelle P. Scott, \\ and James F. A. Traniello \\ Department of Biology, Boston University \\ Boston, Massachusetts 02215
}

\section{INTRODUCTION}

Nicrophorus americanus (Coleoptera: Silphidae), the American burying beetle, was once widespread in its distribution in North America, but has apparently suffered a severe decline in this century and is presently known to occur only on Block Island, Rhode Island and in eastern Oklahoma. Although the natural history, ecology, and reproductive biology of North American and European burying beetles has been described (Pukowski 1933, Milne and Milne 1976, Anderson 1982a, Wilson and Fudge 1984, Wilson and Knollenberg 1984, Wilson et al. 1984, Scott and Traniello 1987, Scott 1988), there is very little information on $N$. americanus except documentation of its past distribution and decline (Davis 1980, Anderson 1982b).

We recently were able to assess the size of the $N$. americanus population on Block Island, and determine the resource requirements for reproduction of this potentially endangered species. In addition, we present information on reproductive behavior, interspecific competition, and correlates of reproductive success.

\section{Methods}

\section{Study Sites}

Studies were conducted on Block Island, Rhode Island. Block Island is located approximately $26 \mathrm{~km}$ southwest of Point Judith, Rhode Island at $71.34^{\circ} \mathrm{W}$ longitude and $41.11^{\circ} \mathrm{N}$ latitude. The habitat occupied by $N$. americanus on Block Island consists of maritime shrub thickets, coastal moraine grassland and agricultural pastures.

*Manuscript received by the editor July 12, 1988. 
marginatus, $N$. orbicollis, and $N$. tomentosus. Additional trapping was conducted on the coastal mainland of Massachusetts and Rhode Island and on the islands of Martha's Vineyard and Nantucket, but yielded no $N$. americanus. Trapping in Michigan, Arkansas, Missouri, North Carolina, Tennessee, Florida, Pennsylvania, New Jersey, and New York also gave negative results (L. Master and D. Schweitzer, personal communication).

\section{Trapping Methods}

$N$. americanus population size was estimated by three methods of live trapping. First, pitfall traps, baited with aged beef kidney placed along a transect at 25 meter intervals; second, a blacklight trap, which was moderately effective in attracting beetles to the ground near the light, and third, whole vertebrate carrion of various types, placed in the field for burial. A total of 467 pitfall trap-nights were logged, in addition to 16 hours of blacklight trapping, and 44 carrion burial traps in five four-day trapping sessions between May 26 and August 1, 1986. Carrion used for burial studies ranged in size from 20 grams to 500 grams and included mice, rats, starlings, chicks, squirrels, snakes, turtles, skates, Japanese quail, and hamsters. For each of these carrion types, a 1.5 meter piece of dental floss was attached to the carcass so it could be located and exhumed after burial. The surrounding vegetation and soil surface were also examined for beetles because unsuccessful competitors are often found near the area of burial (Wilson and Fudge 1984; personal observation). All Nicrophorus individuals captured were identified to species, sexed, measured, and released. Pronotal width was used as an index of an individual's size because it is highly correlated with weight $(\mathrm{r}=0.96, \mathrm{~N}=150)$. Each $N$. americanus was individually marked by lightly sanding the pronotum, painting it with a unique pattern and color(s) of enamel paint, and covering the paint with cyanoacrylate glue.

\section{Population Size Estimation}

A sequential Bayes algorithm (Gazey and Staley 1986) was used to estimate the population size of $N$. americanus on Block Island. This method was used because it was designed specifically for multiple mark-multiple recapture studies with relatively small sample sizes. 


\section{Prey Choice and Competition in Enclosures}

In order to conduct studies on prey choice and interspecific competition, a square screened enclosure measuring $1.3 \mathrm{~m}^{2}$ and $25 \mathrm{~cm}$ high was sunk into the ground to a depth of $10 \mathrm{~cm}$. A 20-liter bucket filled with potting soil was sunk into the ground inside the enclosure and a single carcass was placed on top. To investigate interspecific competition, a male and female $N$. americanus and a male and female $N$. orbicollis were introduced into the enclosure at dusk with a single carcass. The following morning all beetles were collected from the enclosure and the carcass was exhumed to determine which beetle(s) had buried it. Prey choice studies were conducted in a similar manner. A male and female $N$. americanus were placed in the enclosure, and avian and mammalian carcasses were simultaneously available for burial.

\section{Laboratory Studies}

Ten of twenty broods monitored in the laboratory originated from burials in the field enclosure studies on Block Island. The other ten were initiated at Boston University using adults eclosed from laboratory broods. The size of prey used in the laboratory ranged from 60-206 grams. All broods were maintained at a constant temperature of $21^{\circ} \mathrm{C}$ with a 14:10 light:dark cycle. Nine broods were exhumed on the tenth day after burial and all larvae were counted, weighed, and returned to the brood chamber with the carcass and parent(s). Individuals were sexed, measured, and weighed on the day of eclosion.

\section{RESULTS}

A total of $147 N$. americanus ( 84 males, 63 females) were captured on Block Island (Table 1). The sex ratio of males:females captured did not differ significantly from $1: 1\left(\chi^{2}\right.$ test, $\left.p>0.05\right)$. One hundred thirteen $N$. americanus were captured in pitfall traps, 19 at blacklight traps, and 15 on carrion set out for burial. Nicrophorus beetles were trapped repeatedly and successfully on both rainy and windy nights provided the temperature was above $15^{\circ} \mathrm{C}$. Seventeen of 147 (11\%) $N$. americanus were recaptured; 15 individuals (eight females and nine males) were recaptured once and two (females) were recaptured twice. Eight of 17 recaptures occurred within four days of the 
Table 1. Nicrophorus spp. captured on Block Island

\begin{tabular}{lrrrr}
\hline Dates & $\mathrm{Na}$ & $\mathrm{No}$ & $\mathrm{Nm}$ & $\mathrm{Nt}$ \\
\hline $5 / 26-5 / 30$ & 2 & 16 & 10 & 0 \\
$6 / 9-6 / 12$ & $15(2)$ & 20 & 0 & 0 \\
$6 / 24-6 / 28$ & $43(5)$ & 68 & 14 & 2 \\
$7 / 14-7 / 18$ & $80(8)$ & 35 & 8 & 17 \\
$7 / 28-8 / 1$ & $26(4)$ & 34 & 24 & 13 \\
\hline
\end{tabular}

$\mathrm{Na}=N$. americanus, $\mathrm{No}=N$. orbicollis

$\mathrm{Nm}=N$. marginatus, $\mathrm{Nt}=N$. tomentosus

The numbers in parentheses indicate the number of total captures which had previously been captured and marked. Recapture information is available only for N. americanus.

original capture and 15 of 19 recaptures were made in the same location where the individual was originally marked. The population estimate was based on 19 recapture events in five sampling intervals and yielded a mean estimated total population size of 391.4 individuals. The $95 \%$ confidence intervals for the estimated mean were 258,600 .

$N$. americanus showed no significant preference for avian or mammalian carcasses $\left(G=1.061<\chi^{2} .05(2)=5.99\right)$. In our experimental choice situation, the male and female did not always cooperate in burial. The mammalian carcass was chosen by $44 \%$ of the individuals and the avian carcass was chosen by $25 \%(\mathrm{~N}=16)$. In the laboratory, $N$. americanus buried both avian and mammalian carcasses and successfully reared broods on both types of carrion.

In three trials, $N$. americanus outcompeted $N$. orbicollis for prey. In one trial, the male and female $N$. americanus buried the carcass together, and in the other two the male buried the carcass alone while the female remained in the enclosure but was not found with the male in the burial chamber. These results are not surprising, as in Nicrophorus species, size has been shown to be the single most important determinant of success in interspecific competition (Wilson and Fudge 1984; personal observation) and there is almost no overlap in size between $N$. americanus and $N$. orbicollis.

In the field, of 44 carcasses provided for burial, nine were buried by $N$. americanus (20\%), four by $N$. orbicollis $(9 \%)$ and three by $N$. marginatus $(7 \%)$. The remaining carcasses were not buried. $N$. orbicollis primarily buried carcasses ranging from 20-25 grams on Block 
Table 2. Carrion Burials-Field Studies

\begin{tabular}{lrccc}
\hline & & \multicolumn{3}{c}{ Buried By } \\
Prey Size & N & Na & Nm & No \\
\hline $20-25$ & 14 & 0 & 0 & 3 \\
$60-80$ & 5 & 2 & 1 & 1 \\
$80-100$ & 10 & 6 & 2 & 0 \\
$100-200$ & 6 & 0 & 0 & 0 \\
$200-300$ & 2 & 1 & 0 & 0 \\
$>300$ & 7 & 0 & 0 & 0 \\
\hline
\end{tabular}

Species abbreviations are same as those for Table 1.

$\mathrm{N}=$ sample size.

Island. $N$. americanus showed a preference for prey ranging from 80-100 grams. $N$. marginatus also buried prey in this size category (Table 2).

Sixteen of the 20 broods reared in the laboratory resulted in eclosed tenerals. There was a significant positive correlation between carcass weight and total brood weight $(r=0.60, p=0.01$, Fig. 1). There was also a significant positive correlation between the number of tenerals eclosed and carcass weight $(r=0.69, p=.007)$ but no significant correlation between carcass weight and either mean weight or mean pronotal width of tenerals eclosed. A partial correlation analysis removing the effect of total brood weight indicated a highly significant negative correlation between the number of adults eclosed (per brood) and their average weight $(r=-0.77$, $\mathrm{p}=.0001)$.

\section{Discussion}

$N$. americanus is considered to be a potentially endangered species because its distribution may have declined to only two known populations. It is difficult to predict whether the estimated population size of $N$. americanus on Block Island alone is viable for the survival of the species. Fluctuations in environmental factors such as weather, resource availability, changes in vegetation and the presence of parasites or predators can cause natural oscillations in the size of insect populations (New 1984). Human activity can also have a major impact on insect populations.

The Gazey and Staley (1986) population estimate appeared to be the best one to use for $N$. americanus because sample sizes were 


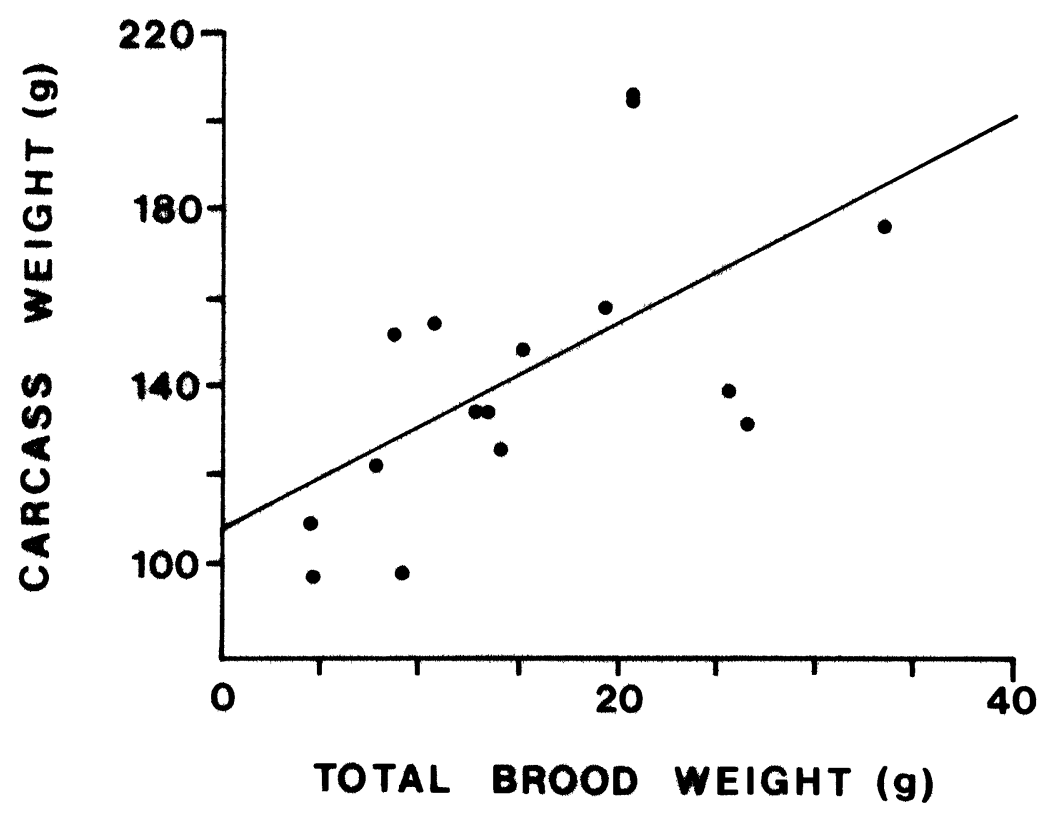

Fig. 1. Relationship of carcass weight to total brood weight.

small and a reasonably narrow confidence interval was desired. However, it should be noted that $N$. americanus violates two assumptions common to virtually all population estimate analyses: 1) that the population size remains constant for the duration of the experiment and 2) that all individuals are equally available for recapture. Because the estimate was made during a two month period, normal mortality and a pulsed recruitment of newly eclosed individuals could have resulted in fluctuations in the size of the population. In addition, at any one time, a proportion of $N$. americanus in a given population will be unavailable for recapture as they will be underground rearing a brood. The latter factor can potentially yield an overestimate of mean abundance if the number of animals actually available for recapture in any one sampling interval is less than the total population because the number of total recaptures may be underestimated.

Maximum numbers of $N$. americanus were captured in pitfall traps in June and there was a decrease in pitfall captures in late July. This is a common pattern for Nicrophorus species (Anderson 1982a, 
Scott unpublished data) although some species have a second population peak in mid to late summer when tenerals emerge. In late July and early August $N$. americanus were still readily captured at carrion. Wilson and Knollenberg (1984) have suggested that pitfall traps provide biased samples as they represent a feeding opportunity rather than a reproductive opportunity. This may explain the decrease in pitfall captures observed on Block Island.

As is generally true of Nicrophorus spp., N. americanus require carrion to bury and use as a reproductive resource and their reproductive behavior is similar to that described for other Nicrophorus species (Pukowski 1933, Wilson and Fudge 1984, Scott and Traniello 1987). Male and female $N$. americanus are attracted to fresh carrion and intrasexual competition occurs within each sex until usually only one male and female remain. Interspecific competition may also occur for possession of a carcass. In one case on Block Island, an $N$. marginatus female was found burying a 60 gram quail on July 30 . The female was found with a male $N$. marginatus on the following day, although the carcass was still not completely buried. The quail was exhumed on August 1 and a male and female $N$. americanus were the only beetles collected with the carrion.

$N$. americanus may cooperate in burying carrion, but individuals of both sexes are capable of burying a carcass alone. Three carcasses (a 90 gram rat, an 87 gram hamster, and a 229 gram chick) were buried by a lone female. Two carcasses were buried alone by a male $N$. americanus, a 70 gram rat and a 90 gram rat. In the former, the male was still alone on the second day after burial, while in the latter, the male was found with a female two days after he had buried the carcass. In all the above examples, the carcasses had been prepared by the parent(s) for the larvae in a fashion similar to that described for other Nicrophorus species (Pukowski 1933, Wilson and Fudge 1984, Scott and Traniello 1987). The carrion is shaved, rolled into a ball, and treated with anal and oral secretions. The female lays eggs in the soil near the carcass and altricial, lightly sclerotized larvae hatch within a few days. The larvae are fed regurgitated food by both the male and female parents. Approximately two weeks after burial the larvae complete development and pupate in the soil nearby. Data from laboratory broods indicate that adults eclose from 48 to 65 days after burial and range in size (pronotal width) from 7.83 to $12.71 \mathrm{~mm}$. The range in size of individuals 
captured in traps on Block Island was 7.98 to $12.63 \mathrm{~mm}$. Females are reproductively capable immediately upon leaving a brood.

Laboratory studies with $N$. americanus showed that reproductive success, measured by total brood weight and by the number of tenerals eclosed, is significantly correlated with carcass size as has also been demonstrated in laboratory broods of $N$. orbicollis (Wilson and Fudge 1984). The significant negative correlation between the number of adults eclosed per brood and their average weight suggests that $N$. americanus individuals rearing broods may make a tradeoff between a large number of small offspring or a small number of large offspring. The outcome of this tradeoff may depend on carcass size, prior reproductive history of the parents, and possibly a prediction of future reproductive opportunities for the offspring.

Collection records from the Museum of Comparative Zoology at Harvard University indicate that $N$. americanus was found in the following states at the early part of this century: Kansas, Illinois, Minnesota, Wisconsin, Virginia, New York, Pennsylvania, Connecticut, New Hampshire, and Massachusetts. Davis (1980) reported additional collections in Tennessee (29 individuals in 1952) and Kentucky (1974). Anderson (1982b) located collection records of $N$. americanus after 1950 only in Ontario, Arkansas, Illinois, Michigan, Missouri, and Tennessee. Ten $N$. americanus individuals have been collected at light traps in Oklahoma (near Tenkiller Ferry Resevoir and in Latimer County) between 1979 and 1988 (L. Master, personal communication). Why has $N$. americanus suffered such a severe decline in what appears to be a relatively short period of time? Studies in enclosures with another species suggest it is unlikely that $N$. americanus has been outcompeted at least in direct confrontation by congeners. Studies with $N$. orbicollis have shown that the preferred carcass size is $20-60$ grams and that carcasses over 60 grams are difficult to bury (Scott unpublished data). $N$. orbicollis may not be a major competitor of $N$. americanus because of a lack of overlap in the size frequency distribution of suitable carcasses and frequent loss in contest competition.

Nicrophorus species diversity is highest at northern latitudes (Scott et al. 1987) and it is likely that congeneric competition would be greatest where species diversity is highest. Size appears to be the most important determinant of success in competition for securing carrion; the largest individuals invariably displace smaller burying 
beetles. Because $N$. americanus are the largest carrion beetles in North America and even the smallest $N$. americanus overlap in size only slightly with the largest $N$. orbicollis and $N$. marginatus, it seems unlikely that $N$. americanus have been outcompeted by other Nicrophorus species. However, factors other than size that might affect the outcome of competition (such as temperature or patterns of activity [Wilson et al. 1984]) remain to be examined.

The decline of $N$. americanus then may be more likely related to the impact of human activity. The widespread use of pesticides has been cited as a potential factor in the decline of non-pest insect populations but there have been few documented losses caused by pesticide use (Pyle et al. 1981, New 1984). This hypothesis initially appears attractive to explain the survivorship of $N$. americanus on Block Island because the island was never sprayed heavily with broad spectrum insecticides such as DDT. However the evidence against this hypothesis includes the following. $N$. americanus has disappeared from numerous other areas where DDT was never sprayed. $N$. americanus was collected in the 1960's from areas which had been sprayed heavily with DDT and lastly, congeners such as $N$. orbicollis and $N$. marginatus, who have a very similar reproductive biology, have apparently suffered no decline in population size.

The habitat(s) occupied by $N$. americanus before its decline was not clearly described so it is very difficult to ascertain how severe an impact the loss of habitat has had on this species. However, the increasing use of land for urbanization and commercial agriculture and forestry has had a demonstrated negative impact on numerous insect species (Pyle et al. 1981). This hypothesis, though tentative, appears to be the most plausible. Although there is no data from this research thus far to draw any significant conclusions about causal factors in the decline of $N$. americanus it is recommended that the search for answers to these questions focus on factors related to changes in, or loss of suitable habitat, that have made it impossible for $N$. americanus to survive today in areas where it was once successful.

\section{ACKNOWLEDGMENTS}

This study was supported by grants from the Nature Conservancy and the Massachusetts Natural Heritage Program. We would like to thank Keith Lewis, Larry Master, Dale Schweitzer, Nancy Breaker, Peter Dunwiddie, and Sam Beshers. 


\section{REFERENCES}

ANDERSON, R. S.

1982a. Resource partitioning in the carrion beetle (Coleoptera: Silphidae) fauna of southern Ontario: ecological and evolutionary considerations. Can. J. Zool. 60: 1314-1325.

1982b. On the decreasing abundance of Nicrophorus americanus Olivier (Coleoptera: Silphidae) in eastern North America: Coleopt. Bull. 36: 362-365.

Davis, L. R.

1980. Notes on beetle distributions with a discussion of Nicrophorus americanus Olivier and its abundance in collections. (Coleoptera: Scarabeidae, Lampyridae and Silphidae). Coleopt. Bull. 34: 245-251.

Gazey, W. J. and M. J. Staley.

1986. Population estimation from mark-recapture experiments using a sequential Bayes algorithm. Ecology 67: 941-951.

MiLne, L. J. AND M. J. MiLne.

1976. The social behavior of burying beetles. Sci. Am. 235: 84-89.

NEW, T. R.

1984. Insect Conservation - An Australian Perspective. Dr. W. Junk Publishers, Dordrecht.

Pukowski, E.

1933. Ökologische untersuchungen an Necrophorus F. Z. Morph. Oekol. 27: 518-586.

Pyle, R., M. Bentzien And P. Opler.

1981. Insect Conservation. Ann. Rev. Ent. 26: 233-258.

ScotT, M. P.

1988. Male parental care and reproductive success in the burying beetle Nicrophorus orbicollis. J. Insect Behavior, in press.

Scott, M. P. and J. F. A. Traniello.

1987. Behavioral cues trigger ovarian development in the burying beetle Nicrophorus tomentosus. J. Insect Physiol. 33: 693-696.

Scott, M. P., J. F. A. Traniello, and I. A. Fetherston.

1987. Competition for prey between ants and burying beetles (Nicrophorus spp): Differences between northern and southern temperate sites. Psyche 94: $325-332$.

WILSON, D. S. AND J. Fudge.

1984. Burying beetles: intraspecific interactions and reproductive success in the field. Ecol. Ent. 9: 195-203.

Wilson, D. S. AND W. G. KNOLLENBERG.

1984. Food discrimination and ovarian development in burying beetles (Coleoptera: Silphidae: Nicrophorus). Ann. Ent. Soc. Am. 77: 165-170.

Wilson, D. S., W. G. KNollenberg, AND J. Fudge.

1984. Species packing and temperature dependent competition among burying beetles (Silphidae, Nicrophorus). Ecol. Ent. 9: 205-216. 

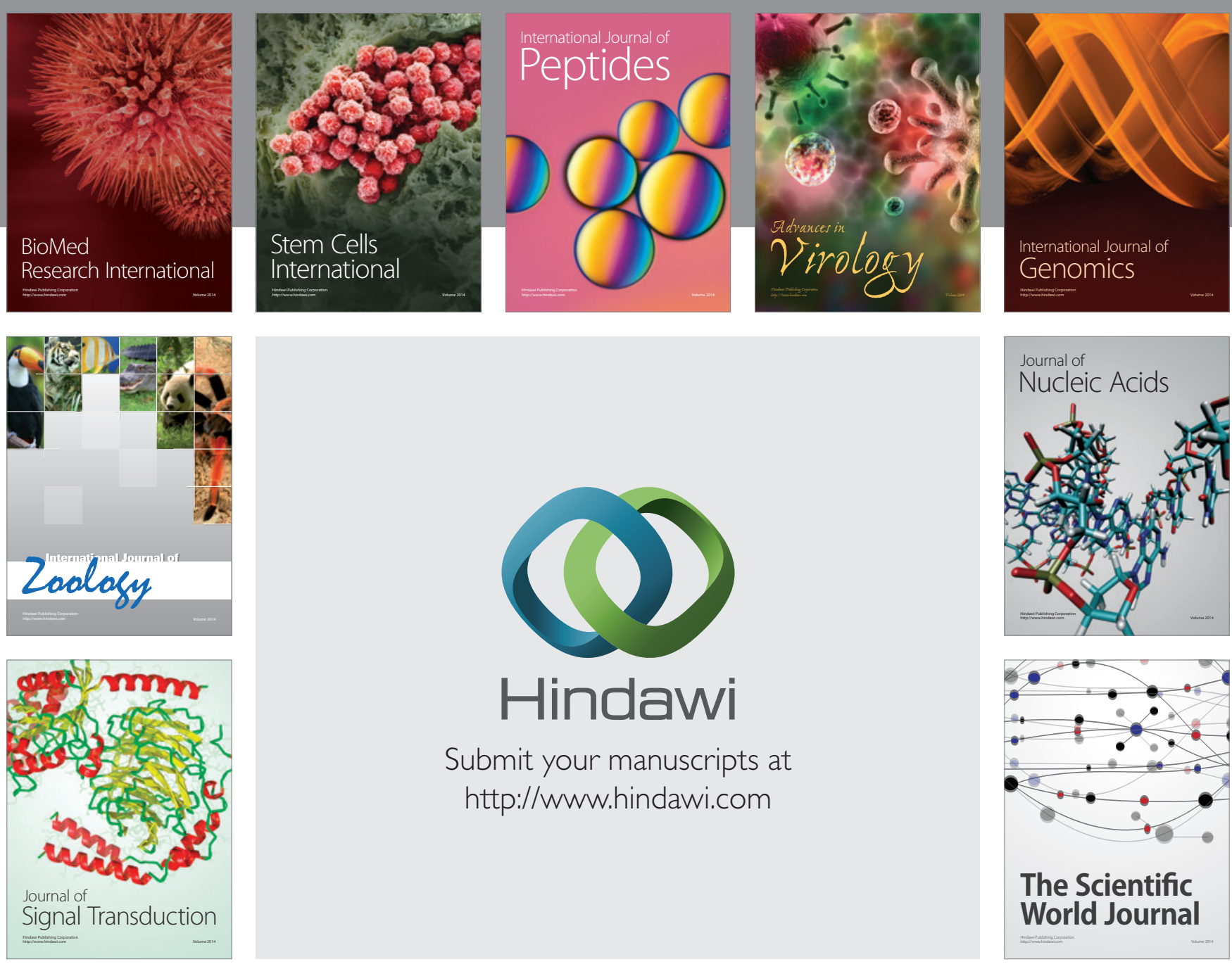

Submit your manuscripts at

http://www.hindawi.com
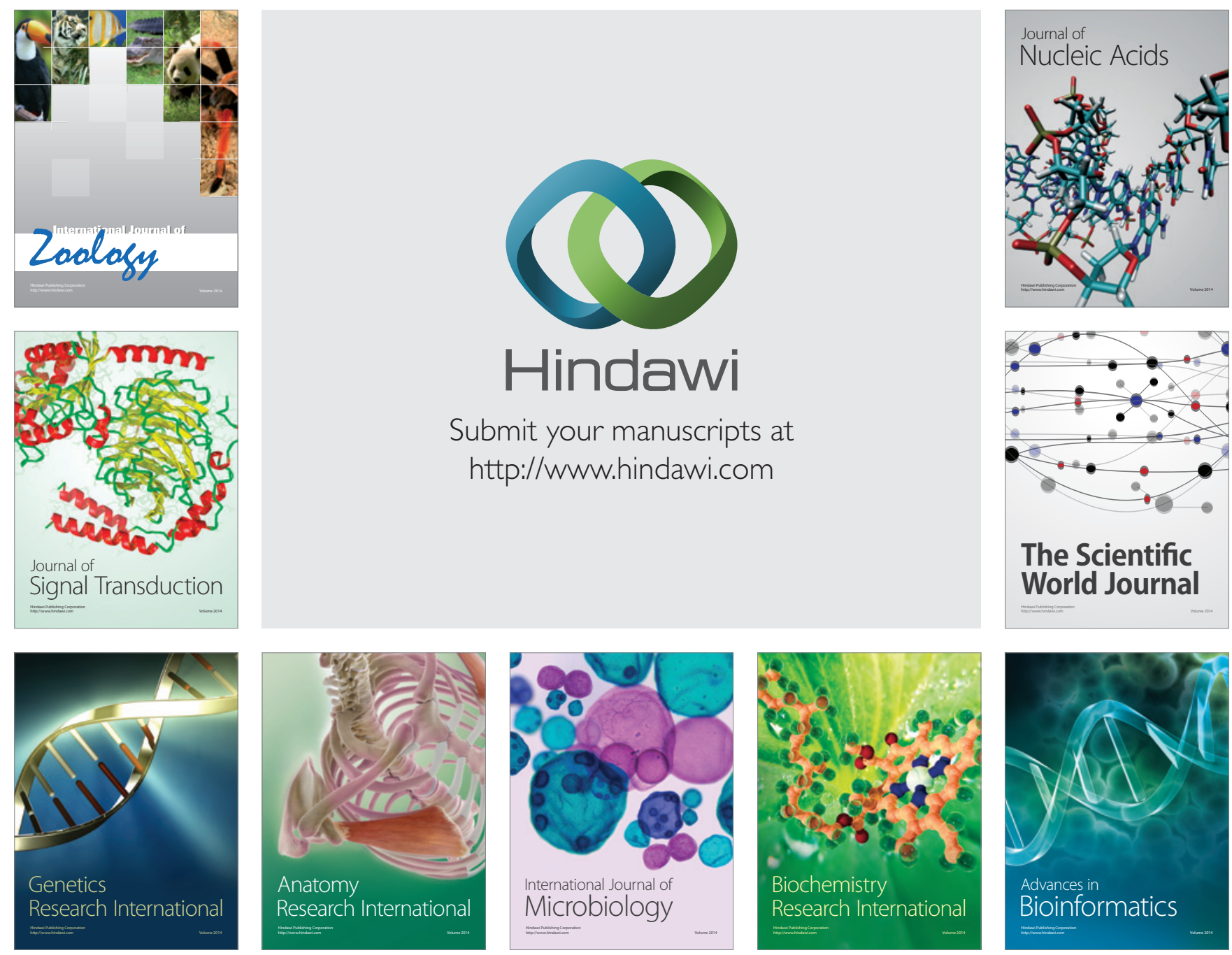

The Scientific World Journal
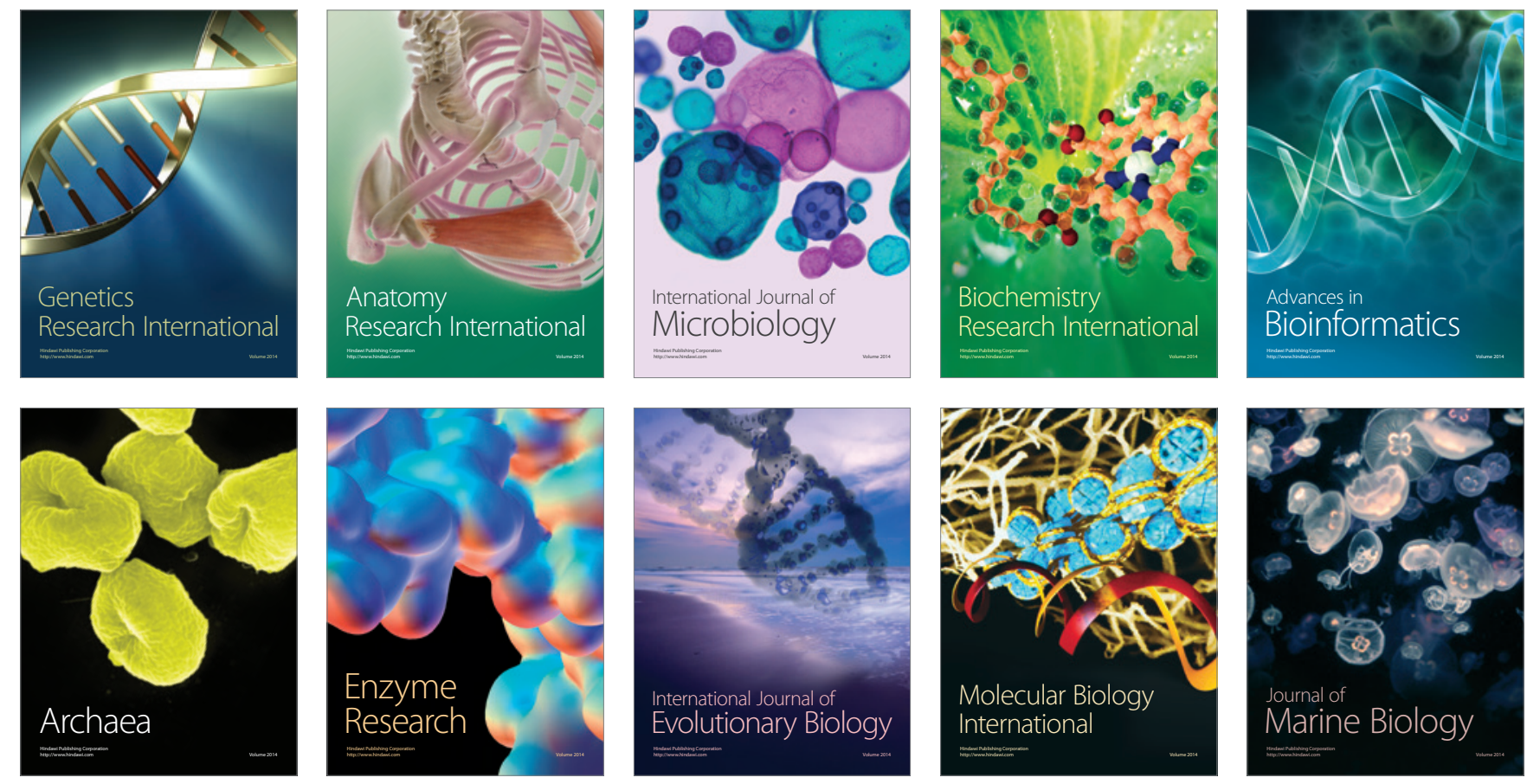